Article

\title{
Digitalization of Public Services-An Input Output Logit Analysis
}

\author{
Shahzadah Nayyar Jehan * and Mudalige Uthpala Indeelinie Alahakoon \\ Graduate School, Tohoku University of Community Service and Science, Tsuruoka 997-0035, Japan; \\ g619001@gs.koeki-u.ac.jp \\ * Correspondence: jehan@koeki-u.ac.jp
}

Received: 22 October 2020; Accepted: 25 November 2020; Published: 3 December 2020

\begin{abstract}
In 2000, Sri Lanka designed an ambitious plan for the introduction of information and communication technology (ICT) in most government functions and in the public service delivery (PSD) system in the country. This process started in the early 2000s and gained momentum with several local and internationally funded initiatives. A systematic innovation concept was incorporated within the ICT regime, which ensured bottom-up learning for a smooth transformation from paper to digitized PSD systems. Towards this end, the Information Communication Technology Agency (ICTA) and Lanka Government Network (LGN) were established. ICT incorporation covered the operations of most government agencies and departments to improve governance and PSD. We analyzed the efficiency of the ICT regime to understand its impact on public service employee output as well as on services to the public. We collected service delivery data from both the employees and their clients using a Likert-scale questionnaire. The questionnaire enquired about the utility of the ICT regime introduced in various departments and ministries (DMs) of the Sri Lankan government. This paper analyzes the overall and relative effectiveness of the ICT regime in terms of the inputs incurred and the outcomes realized. First, we calculated the Cronbach's alpha to test the robustness of the data. Second, we applied ordinal logistics analysis to understand the interrelations among various measures (inputs) and their impacts (outcomes). Finally, we conducted specificity, sensitivity, and predictive value analysis to assess the accuracy of the investigative model. Our findings suggest a positive correlation between the inputs and the outcomes of the ICT regime introduced to digitalize PSD. Our results further indicate that although the inputs and the outcomes are positively corelated, this correlation is not sufficiently strong, and the ICT implementation measures need further emphasis to demonstrate any significant impact on user confidence in this regime.
\end{abstract}

Keywords: ICT; logit regression; public service delivery; Sri Lanka; system innovation

\section{Introduction}

The development of the Internet in the 20th century unlocked the prospects of cooperation across corporations and governments. The 21st century began with internet technology that was both mature and ubiquitous, which led to the amplified cognizance of public rights and greater expectations from public services. The use of information and communication technology (ICT) by developed countries started early on, and many reports find positive consequences of applying ICT in the provision of public services. Both service providers and the public on the receiving end have benefited from its use. Improved communication and efficiency of public service delivery (PSD) are undoubtedly the most ubiquitous benefits of ICT application.

The use of ICT in PSD in developing countries remains considerably low compared to that in many developed countries. Low literacy levels, a lack of training, a lack of initiative, and the scarcity of resources are some of the reasons for this. The coverage of the Internet and social media 
among private sectors and the public occurred before the transition hit government services in many developing countries. The information revolution and greater access to worldwide knowledge prompted a greater demand for better and efficient public services in these countries. In Sri Lanka, the transition toward e-governance was delayed for a long period due to a long, drawn-out civil war in the country. The civil war, which came to an end only in 2009, hindered the prospects for any broad-based changes in the administration in the country for more than 30 years. The economic resources were mostly consumed in fueling the war, and very little could be provided for economic growth and expansion. Arunatilake et al., conducted a detailed study of the costs of the civil war in Sri Lanka and noted that, at times, the civil war cost the country more than the government could produce in terms of GDP [1]. Shyamika also published a paper that covered a wide range of economic and noneconomic impacts of the civil war in the country and showed a similar relationship between the war and the economy [2]. One of the costs of the actions noted by such studies is the delay in the development of important infrastructure in the country. In addition to such studies on war and the economy, several earlier studies evaluated the role of ICT in improving the communication and efficiency of public service delivery.

Hanna produced an exhaustive report on the infrastructural situation in Sri Lanka and showed doubts about the capability of the country to adopt e-governance [3]. It was against this background that the government pushed toward the greater use of ICT and e-governance. This process began in the early 2000s. Several local and internationally funded initiatives were established, and systematic innovation was incorporated within the ICT regime. The systematic innovation ingredient of the regime ensured two-way learning for a smooth transformation from a paper-based system to a digital governance system. To achieve this goal, Information Communication Technology Agency (ICTA) and Lanka Government Network (LGN) were established. The regime covered the operations of most government agencies and departments to improve the efficiency of governance and PSD.

We can find many studies on e-administration; however, the post-implementation perception of ICT regimes has seldom been explored in depth. We present a detailed account of those studies and the subjects covered by them in the following literature review section. Our research concerns understanding the effectiveness and perception of ICT implementation in PSD in Sri Lanka. In this paper, we adopt a bifocal approach and explain the perception of ICT from two perspectives. First, using data gathered from the regime implementers, i.e., the employees, we assessed the efficacy of the regime from an insider's perspective. Second, we analyzed the client's perspective by gathering and analyzing the public service users' data collected in another survey. Finally, we combined the inputs and the outputs and assessed the overall impact of ICT on the public perception of PSD. The results obtained through a rigorous statistical analysis (explained in Section 4) show a reasonable and understandable basis for continuing to invest in the ICT infrastructure, as it has positive bearings upon PSD. Our paper is organized such that after this brief introduction of the context of this study, we present a literature review of the work conducted by other researchers in this regard, followed by the methodology and the data used in our analysis. We then present the results of our analysis, followed by an in-depth discussion of the implications of these results. Finally, we provide an overall summary of the study in the concluding section.

\section{Literature Review}

The turn of the 21st century saw a greater demand for improved PSD; therefore, the impetus for the introduction of ICT in government functions and services gained traction. Biller and Nabi mentioned that many international donor agencies and governments provided substantial funds to introduce and execute large-scale digital transformation in the country [4]. The Sri Lankan government started the e-Lanka project in 2002, and in 2003, the ICTA was established. In addition to these organizations, the LGN was established as a key ICT infrastructure. Digital transformation started in the Sri Lankan government with the establishment of these institutions in earnest. Dissanayake and Lakshman noted that the push toward e-governance was put into motion to improve the efficiency of government 
operations and improve public service delivery at all governmental levels [5]. The regime adopted a bottom-up, transition-based system innovation concept. This gradual scheme of PSD transformation and innovation in the country followed an evolutionary path, and the ensuing implementation experience has largely been smooth and agreeable. Geels noted that "technological transitions are defined as major, long-term technological changes in how society functions, such as transportation, communication, housing and feeding are fulfilled" [6]. Digital transformation adopted a similar path towards this systematic change. Rotmans et al. found that a complete digital transition is preceded by learning processes and developments in small niches of the system and is currently under evolution and evolving [7]. Geels' treatise should be an interesting read for those who wish to develop a deeper conceptual understanding of how sociotechnical system transitions have influenced innovation-based policies targeting system-wide change [8].

Public money is used for the delivery and renovation of public services, making it crucial to assess the usefulness of such spending. The public is therefore obviously interested in understanding the reasoning behind such expenditures. They would like to be assured of the propriety of such spending, i.e., whether the money allocated for service provision is justified. In Sri Lanka, a significant amount of the funds to introduce e-governance and the related ICT regime have come from international donor agencies. Still, a large amount of investment has been allocated from the public exchequer in the last decade. An assessment of the performance of public services is thus necessary. The success of reform will improve public confidence in such measures, and the related expenditures will be able to be justified.

Developing countries can provide limited financial and human resources to initiate and implement a bigger system transformation. However, one should not discount the role governments can play in kickstarting bigger changes despite the lack of internal resources. First, Dawley noted that governments can provide directionality by instituting niches [9]. Second, as suggested by Rotmans et al., governments can create an enabling environment for shared learning processes [7]. Third, as Mazzucato explained, governments can also fund or acquire external funding for research, development, and education [10]. Tanner's study supports connotations like those expounded by Mazzucato [11]. Sri Lanka has been quite active in most of these areas. In a report on the role of ICT in Indian public services, Pardhasaradhi et al. underlined the significant role played by ICT and the related infrastructure in improving the quality of public services [12]. Korneta stressed that it is essential to justify the value of such services in public perception to allow continued support for investments into technologies [13]. Zheng observed, with copious substantiation, that an improvement in service delivery is considered an important performance indicator of e-governance [14]. Alahakoon et al., conducted a post-ICT implementation analysis of public services in Sri Lanka; however, they mainly dealt with organizational efficiency and used a data envelopment approach in their research [15]. Del et al., noted that the concept of e-governance, especially in the context of developing countries, is relatively new and not fully understood [16]. An earlier study about the efficiency of public services in Sri Lanka conducted by the ICTA found that, in the public's perception, most public services in Sri Lanka are not efficient [17]. Currently, after a decade of the introduction of this regime, it is essential to assess the value of the investment and determine where the public services stand in terms of efficiency. Moore found that the effectiveness and efficiency of public services enhance the value of benefits in the public's perception [18]. Thus, as John and Janine noted, it is also essential to provide a framework for service evaluation [19].

\section{Materials and Methods}

\subsection{The Research Questions}

Using field data collected through questionnaires, in this paper, we attempted to find answers to the following questions. 
- How have various ICT measures deployed across the 20 departments and ministries (DMs) of the government of Sri Lanka improved the delivery of PSD represented by customer satisfaction?

- To what extent has satisfaction translated into agreement or disagreement regarding the appropriateness of the measures?

- How are these measures and post-implementation perception thereof connected?

Considering the results thereof, we can provide useful policy and practical operational advice to the handlers of the regime in the country. The results obtained will also be of great importance to researchers who wish to understand the interplays of ICT measures and their implementation in connection with PSD.

\subsection{Data and Materials}

The data were collected through a field survey conducted from February through March of 2020. In total, we surveyed 20 representative DMs of the government of Sri Lanka, where the ICT regime was implemented for ten years starting in 2010. For the questionnaire format details, please refer to Table 1. It was a bifocal survey, containing questions for the regime implementors (officers and employees) about the ICT implementation and for the clients of the PDS. Ten questionnaires were distributed and collected from each of the $20 \mathrm{DMs}$. A similar number of questionnaires were allocated to and collected from the general public. In total, we collected 400 responses, 200 each from each side of the services offered. The questionnaire comprised 20 questions divided into input and outcome questions (inputs for DMs and outcomes for the public). The responses were sought on a Likert scale: 5 standing for strong agreement, 4 for agreement, 3 for neutral, 2 for disagreement, and 1 for strong disagreement. The input questions have been coded as IT, whereas the outcomes have been coded as satisfaction, to reflect the degree of satisfaction the users of the ICT-based PSD had from the regime implementation. Originally, the questionnaires were designed in English and then translated into the Sinhala language, one of the major official languages of Sri Lanka, to assure the ease of the understandability and responses to the questions.

Table 1. Survey questionnaire format

\begin{tabular}{cccccc}
\hline No. of Questions & \multicolumn{5}{c}{ Response } \\
\cline { 2 - 5 } & Strongly Agree & Agree & Neutral & Disagree & Strongly Disagree \\
\hline $\begin{array}{c}\text { Input questions }(1,2,3 \ldots .20) \\
\text { IT (from implementers) }\end{array}$ & 5 & 4 & 3 & 2 & 1 \\
\hline $\begin{array}{c}\text { Outcome questions }(1,2,3 \\
\ldots .20)\end{array}$ & 5 & 4 & 3 & 2 \\
Satisfaction (from the public) & \multicolumn{5}{c}{ Total responses, 400 (200 each from both sides) } \\
\hline Total questions, 20 each side & \multicolumn{5}{c}{} \\
\hline
\end{tabular}

In Table 2, we have listed the DMs from where the survey data were collected. Input- and outcome-related responses of 10 employees from each of the $20 \mathrm{DMs}$ were tabulated along with responses from 10 clients from the same DMs. These DMs were at the center of the ICT regime that was put into place from 2010 and are major PSD hubs for governance and service delivery in Sri Lanka. The data thus collected were recorded in separate Excel sheets and tabulated for further treatment and analysis. The originality of the data sets this study apart from some other studies that were conducted in the past. Additionally, keeping in view the ordinal nature of the data, a transformed binary variable, agree/disagree (AD), was created from the variable "satisfaction" to allow better analysis and understanding of the data outcomes without dropping other variables from the final analysis. The details of the peculiar and novel nature of the analysis are described in the methodology section (Section 3.3) of this paper. 


\subsection{Methodology}

IT was used as an independent variable. Satisfaction is a dependent variable. Another dependent variable, i.e., $\mathrm{AD}$, was used in the data; it is a transformed binary variable for which satisfaction and IT are independent variables. We established a limit of 4 to convert outcomes (satisfaction) into a binary dependent variable $\mathrm{AD}$ of 1 (general agreement) and 0 (overall disagreement). It may be noted that our response data are ordinal on a five-point Likert scale, where 5 stands for strongly agreed, 4 agreed, 3 neutral, 2 disagreed, and 1 for strongly disagreed.

Table 2. Departments and ministries surveyed.

\begin{tabular}{|c|c|c|c|}
\hline & Department/Ministry & $\begin{array}{l}\text { No. of Questionnaires } \\
\text { Collected from Employees }(n 1=200)\end{array}$ & $\begin{array}{l}\text { No. of Questionnaires } \\
\text { Collected from Clients }(n 2=200)\end{array}$ \\
\hline 1. & $\begin{array}{l}\text { Department of } \\
\text { Immigration \& } \\
\text { Emigration }\end{array}$ & 10 & 10 \\
\hline 2. & $\begin{array}{l}\text { Department of Register } \\
\text { of Persons }\end{array}$ & 10 & 10 \\
\hline 3. & $\begin{array}{l}\text { Department of Import } \\
\text { and Export }\end{array}$ & 10 & 10 \\
\hline 4. & $\begin{array}{l}\text { Department of } \\
\text { Examination }\end{array}$ & 10 & 10 \\
\hline 5. & Department of Customs & 10 & 10 \\
\hline 6. & $\begin{array}{l}\text { Department of Motor } \\
\text { Traffic }\end{array}$ & 10 & 10 \\
\hline 7. & $\begin{array}{l}\text { Department of Registrar } \\
\text { General }\end{array}$ & 10 & 10 \\
\hline 8. & Department of Pension & 10 & 10 \\
\hline 9. & Department of Fisheries & 10 & 10 \\
\hline 10. & Department of Railway & 10 & 10 \\
\hline 11. & Department of Labor & 10 & 10 \\
\hline 12. & Ministry of Education & 10 & 10 \\
\hline 13. & Ministry of Healthcare & 10 & 10 \\
\hline 14. & Election Commission & 10 & 10 \\
\hline 15. & Police Commission & 10 & 10 \\
\hline 16. & Foreign Bureau & 10 & 10 \\
\hline 17. & Electricity Board & 10 & 10 \\
\hline 18. & Central Bank & 10 & 10 \\
\hline 19. & $\begin{array}{l}\text { National Transport } \\
\text { Commission }\end{array}$ & 10 & 10 \\
\hline 20. & $\begin{array}{l}\text { Ministry of Foreign } \\
\text { Affairs }\end{array}$ & 10 & 10 \\
\hline
\end{tabular}

Total responses $(n=400)$

To achieve this transformation, for all client responses $\geq 4$, we assigned a value of 1 to this additional variable, and for all responses $<4$, we assigned 0 . In this way, we assumed a careful and conservative approach in handling and analyzing the response data.

First, we present a general analysis of the summary statistics generated from Stata. The summary statistics for all three variables are offered in both tabular and graphic form. Other than numerical and average estimates, we present estimates of the skewness, kurtosis, and coefficient of variation.

Secondly, we calculated Cronbach's alpha to assess the reliability and internal consistency of the data's test items. Moreover, Cronbach's alpha was applied to test the strength and consistency of the data [20]. To calculate Cronbach's alpha, we correlated the score for each scale item with the total score 
for each observation of our survey. Later, we compared that to the variance for all the individual item scores as per the following equation.

$$
\alpha=\left(\frac{j}{j-1}\right)\left(1-\frac{\sum_{i=1}^{k} \alpha_{y_{i}}^{2}}{\alpha_{x}^{2}}\right)
$$

Here, $j$ refers to the number of scale items $\alpha_{y_{i}}^{2}$ refers to the variance associated with item $i$, and $\alpha_{x}^{2}$ refers to the variance associated with the observed total scores.

Furthermore, we present pairwise correlations and Spearman correlations to estimate the degree of interrelation among our three variables. We resorted to Spearman correlations due to the rank-order nature of the data. Additionally, we produced ordinal logistic (Ologit) regression results to deepen our understanding of the nature of the relationship that exists among various variables used in the analysis. The Ologit regression model is a generalization of a binary logistic regression model when the outcome variable has more than two ordinal levels, which in our case were five. Ologit estimates the probability of being at or below a specific outcome level, conditional on a collection of explanatory variables. The ordinal logistic regression model can be expressed as a latent variable model (Long and Freese, 2006; Agresti, 2002) [21,22]. Assume $Y^{*}$ can be defined as a function of a set of predictor variables and a random error. Let $Y^{*}$ be divided by the thresholds $\alpha_{1}, \alpha_{2}, \alpha_{3}, \ldots, \alpha_{j}$, and $\alpha_{1}<\alpha_{2}<\alpha_{3} \ldots<\alpha_{j}$. The values of the observed ordinal variable, $Y$, fall within the regions divided by these thresholds [22]. For example, $Y=0$, if $Y^{*} \leq \alpha_{1}$. The observed ICT satisfaction level as in our survey is the ordinal outcome, y, ranging from 0 to 5 as described in the data section. As the response categories in our data were limited up to 5 , using a nonparametric ordered logistic regression model seemed to be most appropriate for our analytical purpose [19-21]. We can describe our model as [23].

$$
\begin{gathered}
\operatorname{logit}[P(Y \leq j)]=\left[\frac{P(Y \leq j)}{P(Y>J)}\right] \\
=\alpha_{j}-\beta X, j \in[1, J-1]
\end{gathered}
$$

where $j \in[1, J-1]$ are the levels of the ordinal outcome variable $Y$; the proportional odds model assumes there is a common set of slope parameters $\beta$ for the predictors. The ordinal outcomes are distinguished by the $J-1$ intercept $\alpha_{j}$. The benchmark level is $J$. For ordinal regression, we made certain assumptions about the underlying data, i.e., that the response variable was ordinal, and that the explanatory variables were continuous or categorical (though they were ordinal, too). Still, we treated them as either continuous or categorical. We also assumed that there was no multicollinearity, and that the odds were proportional where each independent variable had an identical effect at each cumulative split of the ordinal dependent variable. See Fullerton et al., (2009) [24] and Daniel et al., (2019) [25] for an exhaustive debate and understanding of the issues involved in the application of these types of regression models for the kind of data that were used in this paper. Ananth et al., (1997) also suggest a similar treatment of data in the case of ordinal data [26].

\section{Results}

\subsection{Summary Statistics}

Summary statistics using the bifocal response data $(n=200)$ are presented in Table 3. The summary statistics reflect a noticeable fluctuation in the responses around the mean values. There is a visible skewness in the responses towards the left side, and our input data responses (IT) do reflect a significant kurtosis among the respondents. On the other hand, the data show a relatively lesser degree of skewness amongst the public's perception of the post-ICT-regime-implementation PSD system's performance. Additionally noticeable are the means for IT and satisfaction, representing a level above the neutral scale point of 3. However, as we mentioned in the section on the data and materials (Section 3.1), 
the conservative threshold of 4 for converting our satisfaction variable into the transformed variable of AD resulted in a lower mean value. The additional examination of the summary statistics can be carried out from the chart presented in Figure 1. The chart brings together the information provided in Table 3 in a graphic form for easier understanding and comparison. The graph contains the important summary statistics of all three of our variables, i.e., IT, satisfaction, and agreement/disagreement (AD). The graph in Figure 1 indicates a closer concord between IT and satisfaction. However, there is a visible disparity between IT and AD, which is a transformed binary variable, as we see that the mean values for $\mathrm{AD}$ are lower, whereas the skewness, kurtosis, and coefficient of variation are larger. This is due to a higher value set for the transformation of AD from a five-point scale of satisfaction.

Table 3. Summary statistics.

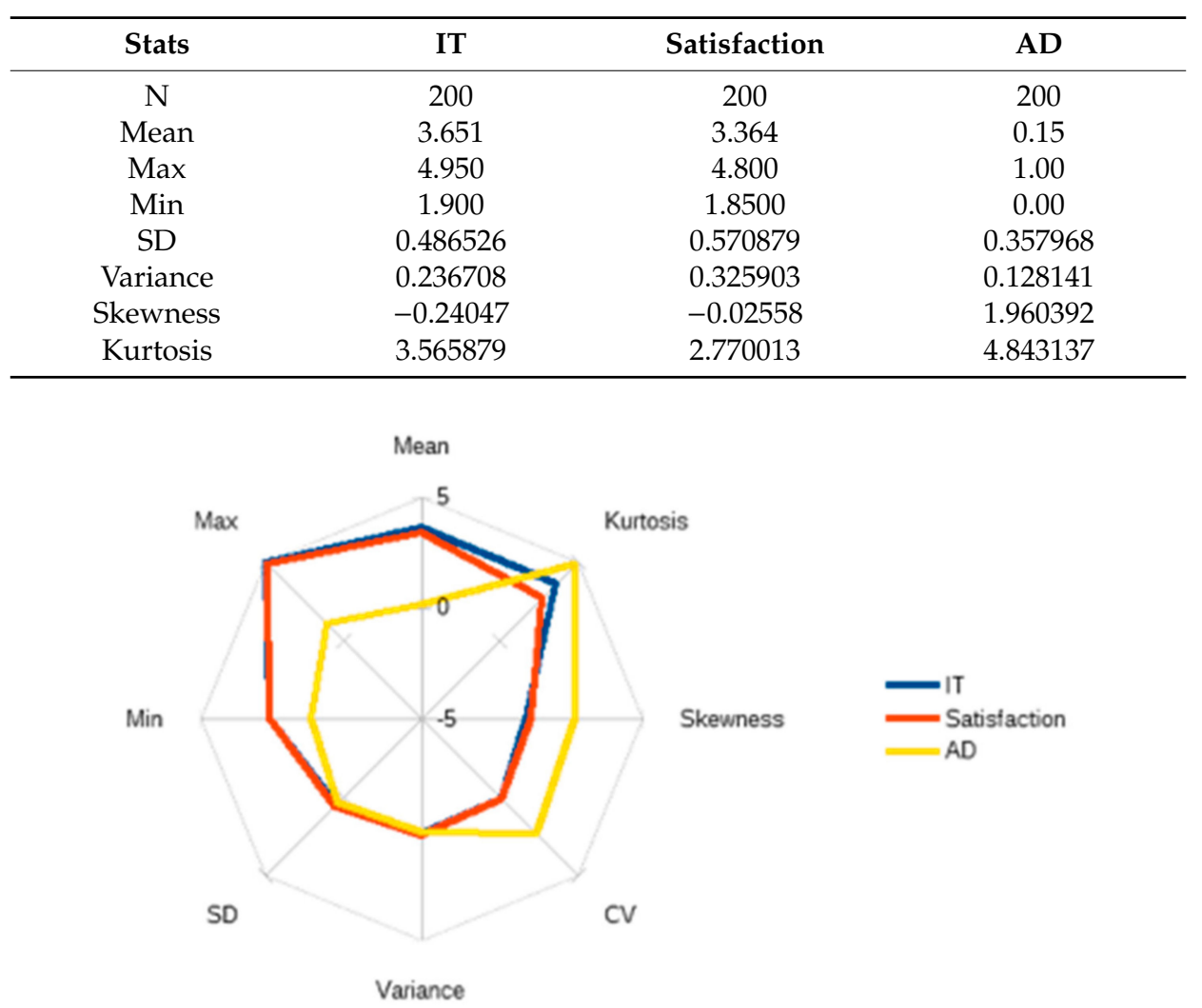

Figure 1. Summary statistics graph $(n=200)$.

\subsection{Data Consistency Test}

Table 4 provides an outline of the consistency analysis of our data. The table consists of a correlated score for each scale item with the total score for each observation of the survey. Then, we have a comparison of that to the variance for all the individual item scores as per the model presented in the methodology section of this paper. While the item-wise correlations range from moderate to vigorous, the inter-item covariances read along the alpha values suggest that our data are fairly consistent and can be used to estimate other relationships, e.g., correlations and regression analysis.

Table 4. Cronbach's alpha.

\begin{tabular}{cccccc}
\hline Item & Obs. & Item-Test Corr. & Item-Rest Corr. & Inter Item Cov. & Alpha \\
\hline IT & 200 & +0.5565 & 0.0939 & 0.1336055 & 0.7410 \\
Satisfaction & 200 & +0.8394 & 0.4560 & 0.0106533 & 0.1104 \\
AD & 200 & +0.7478 & 0.5123 & 0.0281520 & 0.1819 \\
Test scale & - & - & 0.0574703 & 0.4995 & - \\
\hline
\end{tabular}




\subsection{Correlations}

Table 5 shows the pairwise correlation estimates for IT, satisfaction, and AD. We can see that IT and $\mathrm{AD}$ are reasonably and positively correlated. Additionally, satisfaction and AD are positively correlated to a similar extent. However, what is worrying is that the IT measures adopted to date have little strong correlation with the satisfaction levels of the customers. It is therefore essential that some measures of the ICT regime are recalibrated in order to achieve higher levels of customer satisfaction. Our response data are rank ordered for both the ICT inputs and the outcomes. It was, therefore, more appropriate to investigate beyond the usual pairwise correlations to obtain a better picture of the relationships between the three, i.e., IT, satisfaction, and AD. It should be noted that a positive

Table 5. Pairwise correlations $(n=200)$.

\begin{tabular}{cccc}
\hline & IT & Satisfaction & AD \\
\hline IT & 1.0000 & - & - \\
Satisfaction & 0.1014 & 1.0000 & - \\
AD & 0.6612 & 0.6538 & 1.0000 \\
\hline
\end{tabular}

Spearman correlation coefficient corresponds to an increasing monotonic trend between the sets of our three factors under investigation in this study. The Spearman results are presented here (Table 6), and we find a weak correlation between IT and satisfaction; the situation between IT and AD is similar. However, the Spearman correlation indicates a relatively stronger positive correlation between the satisfaction and $\mathrm{AD}$, somewhat like the results depicted by the pairwise correlation. Here, too, we can conclude that the ICT regime has not lived up to expectations, and the results have not positively impacted the end-users of the regime. Thus, there is a need to further explore and see what is lacking in the regime to assure higher levels of satisfaction.

Table 6. Spearman correlations $(n=200)$.

\begin{tabular}{cccc}
\hline Item & IT & Satisfaction & AD \\
\hline IT & 1.0000 & - & - \\
Satisfaction & 0.0888 & 1.0000 & - \\
AD & 0.0740 & 0.6188 & 1.0000 \\
\hline
\end{tabular}

\subsection{Ologit Regression}

Table 7 provides the results of an ordered logistic regression based upon the model we explain in the methodology section above in this paper. As we can see from the testing of the model (prob. $>\mathrm{chi}^{2}$ ), we found that the model fits with our data and can lead us to some meaningful conclusions. This suggests that using the model will be appropriate, and our test statistic, i.e., z-test, will explain the relationship between the dependent and independent variables with an acceptable confidence level $(95 \%$ in this case). We found that all the $\mathrm{z}$ values were significant, and thus, we can conclude a strong dependence of satisfaction on the ICT regime. All our $P>|z|$ values are less than 0.05 (for $95 \%$ confidence), which points to the fact that the regime's reform measures have had a strong bearing upon the efficiency of the BPR regime. 
Table 7. Ordered logistic regression.

\begin{tabular}{|c|c|c|c|c|c|c|}
\hline \multicolumn{5}{|c|}{ Log likelihood $=-738.58902$} & \multicolumn{2}{|c|}{$\begin{array}{r}\mathrm{n}=200 \\
\text { LR chi2(1) }=1.82 \\
\text { Prob }>\text { chi2 }=0.1771 \\
\text { Pseudo R2 }=0.0012\end{array}$} \\
\hline Satisfaction & Coef. & Std. Err. & $\mathbf{z}$ & $P>|z|$ & \multicolumn{2}{|c|}{ 95\% Conf. Interval } \\
\hline IT & 1.432329 & 0.5958207 & 0.860 & 0.0388 & 0.6338111 & 3.236875 \\
\hline _Cons & 1.432329 & 0.0731656 & -1.970 & 0.0490 & 0.0022293 & 0.992195 \\
\hline
\end{tabular}

\subsection{Sensitivity and Specificity Test}

Sensitivity and specificity tests were carried out for the AD, and the results are presented in Table 8 and show the sensitivity and specificity results for our model. A straightforward way of measuring accuracy is simply observing the proportion of responses that were correctly classified, i.e., the proportions of true positives and true negatives. It should be noted that the sensitivity measure reveals the proportion of observed positives that were predicted to be positive. The specificity is the proportion of observed negatives that were predicted to be negatives. The earlier part of the table sets the rules that define the sensitivity and specificity of the data. The latter part shows our results, and we can rest assured that our data and model suit each other well and that the results thus generated are neither falsely true nor falsely false.

Table 8. Sensitivity and specificity for AD.

\begin{tabular}{|c|c|c|c|}
\hline \multirow{2}{*}{ Classified } & \multicolumn{3}{|c|}{ True - Tru } \\
\hline & $\mathbf{D}$ & $\sim \mathrm{D}$ & Total \\
\hline+ & 0 & 0 & 0 \\
\hline- & 30 & 170 & 200 \\
\hline Total & 30 & 170 & 200 \\
\hline \multicolumn{4}{|c|}{ Classified + if predicted $\operatorname{Pr}(\mathrm{D})>0.5$, True $\mathrm{D}$ defined as AD! $=0$} \\
\hline Sensitivity & & & $0.00 \%$ \\
\hline Specificity & & & $100.00 \%$ \\
\hline Positive predictive value & & & $0.00 \%$ \\
\hline Negative predictive value & & & $85.00 \%$ \\
\hline False + rate for true $\sim \mathrm{D}$ & & & $0.00 \%$ \\
\hline False - rate for true D & & & $100.00 \%$ \\
\hline False + rate for classified + & & & $0.00 \%$ \\
\hline False - rate for classified - & & & $15.00 \%$ \\
\hline Correctly classified & & & $85.00 \%$ \\
\hline
\end{tabular}

\section{Discussion}

Despite having suffered from internal political strife, Sri Lanka has come a long way in adapting to modern information age systems. The major push started with the establishment of certain ICT-related institutions in the country, as explained in the introduction, which led to observable procedural changes in governance and public services. These changes have not been smooth or without glitches either. A respite from internal strife allowed the country to divert attention and resources towards providing better and information technology-based services to its public. The changes and the investments were put into effect with the expectations of better and efficient governance and PSD. Understanding the effectiveness and perception of the ICT regime implementation process in the PSD infrastructure of the government of Sri Lanka will serve as a key factor to support these transformative efforts. Our data and analysis point towards an obvious and positive relationship between the ICT measures and their outcomes. 
In Sri Lanka, this transformation took effect gradually, and it evolved over time. The regime encompassed a complete system transformation, with the innovation of public service processes at its foundation. This paper has a bi-focal approach, a service-provider-focus and a service recipient focus, and it explains the perception of ICT from both foci. Using a diagnostics approach favored by Shapiro (1997), we compared the inputs and the outputs to assess how the regime has changed the post-ICT-implementation public perception of PSD [27]. The results obtained through a rigorous statistical analysis show that there is a reasonable and understandable basis for continuing to invest in the infrastructure, as it has had positive bearings upon the PSD in Sri Lanka. We conducted a nonparametric ordered logistic analysis. Chaya (2004) noted that analyzing survey data beyond descriptive statistics always comes with a particular uncertainty as to which analytical approach will offer the best analysis of the data [28]. Hand (2020) also stated that handling survey data is fraught with pitfalls, and great care must be taken when concluding the descriptive statistical analysis [29]. While some would suggest using a logistic regression model, there are multiple options that need to be carefully considered because of the nature of the data. The problem is more acute, as the responses to the question do contain a certain level of subjective evaluation. As our questionnaire asked respondents to answer the questions on a five-point Likert scale ( 5 for strongly agreed ... and 1 for strongly disagreed), we needed to use a regression approach that could take care of the ordinal nature of the data. Hence, we decided to use ordinal logistic regression to analyze our data. This approach allowed us a deeper understanding of the interrelationships amongst our independent and dependent variables while attending to most of the issues with the nature of the data.

The summary statistics reveal that for most of our observed variables, the mean values are above 3 but below 4, i.e., a mean response towards the ICT measures. The mean for outcomes reflects a comparatively better level of agreement amongst our surveyed population about the expected performance of the regime. Our results related to paired correlations reflect a positive correlation between the independent and dependent variables, which means that the efficiency of the PSD is explained by the ICT regime's reform initiatives [30]. The Spearman correlations adjusted for the ordinal and ranked nature of the data. The Spearman results emphasize the parallel connection between the ICT measures and user satisfaction. We also conducted an ordinal logistic regression analysis to understand the nature of the relationship between our variables. We ran a test of the model and found that the model fits with our data and can lead us to some meaningful conclusions. This suggested that using our model will be appropriate, and our test statistic, i.e., the z-test, will explain the relationship between the dependent and independent variables with an acceptable confidence level (95\% in this case). The results indicate that all the $\mathrm{z}$ values are significant, and thus, we can conclude that there is a strong dependence of satisfaction on the ICT regime. Additionally, all the $\mathrm{P}>|\mathrm{z}|$ values are less than 0.05 (for 95\% confidence), again pointing towards the fact that the regime's reform measures have had a strong bearing upon the satisfaction from the ICT regime. Finally, sensitivity and specificity tests were carried out for the for $\mathrm{AD}$, and the results show sensitivity and specificity results for our model. It should be noted that the sensitivity measure reveals the proportion of observed positives that were predicted to be positive. The specificity is the proportion of observed negatives that were predicted to be negatives.

Earlier studies on similar issues by these authors, performed with a different approach and analytical techniques, might be of interest to the readers. Jehan et al., (2010a) presented an interesting study where they presented their findings of e-governance in Sri Lanka; however, the paper is related to much earlier stages of the e-governance in the country [31]. Jehan et al. (2010b) conducted another study about the business process and change management in Sri Lanka; again, the focus was more on presenting a change management model in the country. [32]. In a more recent study by Elapatha et al., (2020), an analytical approach like ours was used; however, that paper is about business process reengineering in the country [33]. Alahakoon et al., (2020) published a study on ICT in Sri Lanka; however, that paper is about the operational and technical efficiency of the various departments per se and used a data envelopment approach [15]. Summing up the discussion, we can say that the data, 
the analytical approach, and the issues raised in this paper are unique, and the results carry significant academic, analytical, and practical significance.

\section{Conclusions}

The Sri Lankan transition toward e-governance through adaptation via a broad ICT regime is a welcome development and a change in a country that has been through difficult and prolonged internal political strife. The respite from the conflict in the first decade of the 20th century opened up opportunities for such important initiatives in the country. Our aim in this paper was to estimate the perception of the ICT measures in a post-implementation scenario. Our paper analyzed the effectiveness and acceptability of the ICT regime in Sri Lanka. The results show that the inputs of the regime are positively contributing to the success of the program. At the same time, we would like to acknowledge that the contribution has not reached very significant levels to date. This relationship is evidenced by the results of the summary statistics, various correlation measures, and the ordinal logistics analysis. We did take specific care with the data and calculated the Cronbach's alpha to test the robustness of the data. Finally, we conducted specificity, sensitivity, and predictive value analysis to assess the accuracy of the model applied. Our findings suggest a positive though, at times, a weak correlation between the inputs and the outcomes of the ICT regime put into place to digitalize the PSD in the country. Additionally, sensitivity and specificity tests were carried out for the AD, and the results show sensitivity and specificity results for our model. The uniqueness and originality of our data make the study first of its kind, and it could be of enormous use to both PSD operators and researchers who plan to build upon our results and find other angles to a case in point. One such piece of research may be the exploration of factor efficiencies per se by applying other techniques of inquiry. The authors plan to expand the scope of study in the future by also examining the factor efficiencies in the system.

Author Contributions: Conceptualization, S.N.J. and M.U.I.A.; methodology, S.N.J. and M.U.I.A.; formal analysis, S.N.J. and M.U.I.A.; resources, S.N.J. and M.U.I.A.; data curating, M.U.I.A.; writing-Original draft preparation, S.N.J. and M.U.I.A.; writing-Review and editing, S.N.J. and M.U.I.A.; visualization, S.N.J. and M.U.I.A.; supervision, S.N.J. All authors have read and agreed to the published version of the manuscript.

Funding: This research received no external funding.

Acknowledgments: The authors are deeply thankful to the employees and clients of various departments and ministries of the government of Sri Lanka who replied to the questionnaires.

Conflicts of Interest: The authors declare no conflict of interest.

\section{References}

1. Arunatilake, N.; Jayasuriya, S.; Kelegama, S. The Economic Cost of the War in Sri Lanka. World Dev. 2001, 29, 1483-1500. [CrossRef]

2. Shyamika, J.S. Lost in transition: Linking war, war economy and post-war crime in Sri Lanka. Third World Themat. A TWQ J. 2018, 3, 63-79. [CrossRef]

3. Hanna, N.K. From Envisioning to Designing e-Development: The Experience of Sri Lanka. Directions in Development; Information and Communication Technologies; World Bank: Washington, DC, USA, 2007; Available online: https://openknowledge.worldbank.org/handle/10986/6628 (accessed on 20 November 2020).

4. Biller, D.; Nabi, I. Investing in Infrastructure: Harnessing Its Potential for Growth in Sri Lanka. Directions in Development-Infrastructure; World Bank: Washington, DC, USA, 2013; Available online: https://openknowle dge.worldbank.org/handle/10986/15810 (accessed on 20 October 2020).

5. Dissanayake, S.; Lakshman, D. Development of E-Governance in Sri Lanka. In Digital Public Administration and E-Government in Developing Nations: Policy and Practice; Edward Francis, H., Ed.; IGI Global: Hershey, PA, USA, 2013; pp. 307-316. [CrossRef]

6. Geels, F.W. Technological transitions as evolutionary reconfiguration processes: A multi-level perspective and a case-study. Res. Policy 2002, 31, 1257-7124. [CrossRef]

7. Rotmans, J.; Kemp, R.; Asselt, M. More evolution than revolution. Transition management in public policy. Foresight 2001, 3, 15-31. 
8. Geels, F.W. Technological Transitions and System Innovations; Edward Elgar Publishing: Cheltenham, UK, 2005.

9. Dawley, S. Creating New Paths? Offshore wind, policy activism, and peripheral region development. Econ. Geogr. 2014, 90, 91-112.

10. Mazzucato, M. The Entrepreneurial State: Debunking Public vs. Private Sector Myths; Anthem Press: London, UK, 2015.

11. Tanner, A.N. Regional branching reconsidered: Emergence of the fuel cell industry in European regions. Econ. Geogr. 2014, 90, 403-427. [CrossRef]

12. Pardhasaradhi, Y.; Bagga, R.K.; Vijaya, K.S.; Sekhar, Y. "Role of ICT Infrastructure in Public Service Delivery." A Report on ICT and Infrastructure, Report No: IIIT/TR/2013/-1. 2013, pp. 47-52. Available online: http://web2py.iiit.ac.in/research_centres/publications/download/inproceedings.pdf.9c97e6849a0acbf9.4353 49323031332d526f6c654f66494354496e6672617374727563747572652d436f6e76656e74696f6e50726f2d34372d 35322e706466.pdf (accessed on 18 November 2020).

13. Korneta, P. Critical success factors for Polish agricultural distributors. Br. Food J. 2019, 121, 1565-1578. [CrossRef]

14. Zheng, Y. Explaining Citizens' E-Participation Usage: Functionality of E-Participation Applications. Adm. Soc. 2017, 49, 423-442. [CrossRef]

15. Alahakoon, M.U.I.; Jehan, S.N. Efficiency of Public Service Delivery-A Post-ICT Deployment Analysis. Economies 2020, 8, 97. [CrossRef]

16. Del, S.; Carlotta, R.L.O.; Emanuele, P. Governing the public sector e-performance: The accounting practices in the digital age. In Decision Management: Concepts, Methodologies, Tools, and Applications; IGI Global: Hershey, PA, USA, 2017.

17. ICTA. Government Organizations Visitors' Survey, Information Communication Technology Agency of Sri Lanka, 2008, Colombo. Available online: www.icta.lk/ (accessed on 20 November 2020).

18. Moore, M. Creating Public Value: Strategic Management in Government; Harvard University Press: Cambridge, MA, USA, 1995.

19. John, A.; Janine, O. Making Sense of Public Value: Concepts, Critiques and Emergent Meanings. Int. J. Public Adm. 2009, 32, 171-191.

20. Tavakol, M.; Reg, D. Making sense of Cronbach's alpha. Int. J. Med Educ. 2011, 2. [CrossRef] [PubMed]

21. Long, J.S.; Freese, J. Regression Models for Categorical Dependent Variables Using Stata, 2nd ed.; Stata Press: Station, TX, USA, 2006.

22. Agresti, A. A model for repeated measurements of a multivariate binary response. J. Am. Statist. Assoc. 1997, 92, 315-321. [CrossRef]

23. Liu, X.; Koirala, H. Ordinal Regression Analysis: Using Generalized Ordinal Logistic Regression Models to Estimate Educational Data. J. Mod. Appl. Stat. Methods 2012, 11, 21. [CrossRef]

24. Fullerton, A.S. A Conceptual Framework for Ordered Logistic Regression Models. Sociol. Methods Res. 2009, 38, 306-347. [CrossRef]

25. Daniel, F.; Ivy, L.; Roy, C. A method for ordinal outcomes: The ordered stereotype model. Int. J. Methods Psychiatr. Res. 2019, 28, e1801. [CrossRef]

26. Ananth, C.V.; Kleinbaum, D.G. Regression models for ordinal responses: A review of methods and applications. Int. J. Epidemiol. 1997, 26, 1323-1333. [CrossRef]

27. Shapiro, D.E. The interpretation of diagnostic tests. Stat. Methods Med. Res. 1999, 8, 113-134. [CrossRef]

28. Chaya, S.M.; Margaret, S.P. Quantifying and comparing the predictive accuracy of continuous prognostic factors for binary outcomes. Biostatistics 2004, 5, 113-127. [CrossRef]

29. Hand, D.J. Classifier Technology and the Illusion of Progress. Stat. Sci. 2006, 21, 1-14. [CrossRef]

30. Kumar, V.; Tan, P.; Steinbach, M. Data mining. In Handbook of Data Structures and Applications; Mehta, D.P., Sahni, S., Eds.; Chapman \& Hall: London, UK; CRC Press: Boca Raton, FL, USA, 2005; pp. 1-22.

31. Jehan, S.N.; Nishantha, G.G.D.; Jehan, S.Q. E-governance initiative in Sri Lankan public service delivery. In Proceedings of the 12th International Conference on Advanced Communication Technology (ICACT), Gangwon-Do, Korea, 7-10 February 2010; pp. 1625-1629. 
32. Jehan, S.N.; Nishantha, G.G.D.; Uchida, Y. BPR in large public organizations: A case of managing change in a developing country. J. Jpn. Assoc. Manag. Syst. 2010, 27, 25-31.

33. Elapatha, V.W.; Jehan, S.N. An Analysis of the Implementation of Business Process Re-engineering in Public Services. J. Open Innov. Technol. Mark. Complex. 2020, 6, 114. [CrossRef]

Publisher's Note: MDPI stays neutral with regard to jurisdictional claims in published maps and institutional affiliations.

(C) 2020 by the authors. Licensee MDPI, Basel, Switzerland. This article is an open access article distributed under the terms and conditions of the Creative Commons Attribution (CC BY) license (http://creativecommons.org/licenses/by/4.0/). 